\title{
Paths of introduction: Assessing global colonization history of the most successful amphibian invader
}

\author{
Gabriel Jorgewich-Cohen ${ }^{1}$, Rachel Montesinos ${ }^{2}$, Rafael Henrique ${ }^{1}$, Felipe Toledo ${ }^{3}$, Amaël \\ Borzée $^{4}$, Yang $\mathrm{Yi}^{5}$, Wang Fei ${ }^{6}$, Takeshi Igawa ${ }^{7}$, Juan Guayasamin ${ }^{8}$, Gabriel Laufer ${ }^{9}$, \\ Wilmar Bolivar ${ }^{10}$, Ariel Rodriguez ${ }^{11}$, and Taran Grant ${ }^{1}$ \\ ${ }^{1}$ Universidade de São Paulo \\ ${ }^{2} \mathrm{UFMG}$ \\ ${ }^{3}$ UNICAMP \\ ${ }^{4}$ Nanjing Forestry University \\ ${ }^{5}$ Xishuangbanna Tropical Botanical Garden \\ ${ }^{6}$ ShanghaiTech University \\ ${ }^{7}$ Hiroshima University \\ ${ }^{8}$ Universidad San Francisco de Quito \\ ${ }^{9}$ Museo Nacional de Historia Natural \\ ${ }^{10}$ Universidad del Valle \\ ${ }^{11}$ Tierarztliche Hochschule Hannover
}

December 7, 2020

\begin{abstract}
International socioeconomic relationships form the background that underlies the history of invasive species. Species with economic value, such as the North American bullfrog (Lithobates catesbeianus), are more likely to become internationally distributed and to be subsequently introduced to non-native areas and, consequently, become more difficult to control. Using population genetics methods, we investigated the invasion pathways, the connectivity among clusters in different countries and the native population of origin of globally introduced bullfrog populations. Throughout the analysis of seven microsatellite nuclear loci, one fragment of the mitochondrial cytochrome b locus, and historical information, four main lineages were identified and analyzed along with previous findings. This species' capability to colonize several countries from few starting lineages highlights the necessity to control new propagule pressure to ensure successful management programs, as high inbreeding and bottleneck effect seem not to diminish the invasive success of this species. There is a consensus between markers that most areas of South America belong to the same genetic population while populations in Asia have a more complex history of introduction.
\end{abstract}

Paths of introduction: Assessing global colonization history of the most successful amphibian invader

Gabriel Jorgewich-Cohen ${ }^{1} \mid$ Rachel Montesinos $^{2} \mid$ Rafael dos Santos Henrique $^{1} \mid$ Luís Felipe Toledo $^{\mathbf{3}} \mid$ Amaël Borzée4 | Yang Yi5 | Wang Fei6 | Takeshi Igawa7 | Juan M. Guayasamin8 | Gabriel Laufer9 | Wilmar Bolívar $^{1} 0$ | Ariel Rodríguez ${ }^{11}$ | Taran Grant ${ }^{1}$

1 Laboratório de Anfíbios, Biosciences Institute, University Of São Paulo. São Paulo, SP, Brazil

2 Laboratório de Herpetologia, Departamento de Zoologia, Instituto de Ciências Biológicas, Universidade Federal de Minas Gerais. Belo Horizonte, MG, Brazil 
3 Laboratório de História Natural de Anfíbios Brasileiros (LaHNAB), Departamento de Biologia Animal, Universidade Estadual de Campinas. Campinas, SP, Brazil

4 Laboratory of Animal Behavior and Conservation, College of Biology and the Environment, Nanjing Forestry University, China

5 Center for Integrative Conservation, Xishuangbanna Tropical Botanical Garden, Chinese Academy of Sciences. Yunnan, China

6 School of Life Science and Technology, Shanghaitech University. Shanghai, China

7 Amphibian Biology Center, Hiroshima University, Higashihiroshima. Hiroshima, Japan

8 Laboratorio De Biología Evolutiva, Instituto BIÓSFERA-USFQ, Colegio De Ciencias Biológicas Y Ambientales COCIBA, Campus Cumbayá, Universidad San Francisco De Quito USFQ. Quito, Ecuador

9 Area Biodiversidad y Conservacion, Museo Nacional de Historia Natural. Montevideo, Uruguay

10 Research Group in Animal Ecology, Department of Biology, Universidad Del Valle. Cali, Colombia

11 Institute of Zoology, University of Veterinary Medicine Hannover (TiHo)

\section{Correspondence}

Gabriel Jorgewich-Cohen

Bioscience Institute, University of São Paulo, Rua do Matão, 101, Cidade Universitária, CEP 05508-090, São Paulo, SP, Brazil

Email: gabrieljcohen2@gmail.com

\section{Funding information}

Grants and fellowships were provided by Sao Paulo Research Foundation (FAPESP \#2012/10000-5; \#2016/25358-3; \#2018/15425-0; \#2019/18335-5), and the National Council for Scientific and Technological Development (CNPq \#134290/2015-1; \#300896/2016-6; \#306823/2017-9)

\section{Abstract}

International socioeconomic relationships form the background that underlies the history of invasive species. Species with economic value, such as the North American bullfrog (Lithobates catesbeianus ), are more likely to become internationally distributed and to be subsequently introduced to non-native areas and, consequently, become more difficult to control. Using population genetics methods, we investigated the invasion pathways, the connectivity among clusters in different countries and the native population of origin of globally introduced bullfrog populations. Throughout the analysis of seven microsatellite nuclear loci, one fragment of the mitochondrial cytochrome b locus, and historical information, four main lineages were identified and analyzed along with previous findings. This species' capability to colonize several countries from few starting lineages highlights the necessity to control new propagule pressure to ensure successful management programs, as high inbreeding and bottleneck effect seem not to diminish the invasive success of this species. There is a consensus between markers that most areas of South America belong to the same genetic population while populations in Asia have a more complex history of introduction.

\section{KEYWORDS}

Amphibia, Anura, globalization, invasion biology, population establishment

\section{Introduction}

Human action influence natural environments in many ways, often with unintended consequences. One of the most significant phenomena that substantially increased with globalization is the invasion of alien species. Together with habitat loss, it is the main reason for native species' populations decrease and extinction (Lowe 
et al., 2000; Scheele et al., 2019). Invasive species control efforts are expensive and commonly ineffective (Ficetola \& Scali, 2010; Hulme, 2006), resulting in the necessity to understand invasion pathways to avoid the colonization of new species or the release of new propagules that might increase genetic variability and fitness of already established populations (Kolbe et al., 2004).

Alien species are sometimes intentionally spread for economic reasons, such as agriculture, biological control, and pet trade (Chiaverano et al., 2014; Ng \& Lim, 2010). In these cases, human history can be a useful tool to help identifying and explaining translocation events. It is also common to find information in the lay literature that can help elucidate the origin and pathways of introduction. However, gathering and interpreting information from such literature around the globe can be difficult due to access limitations, language differences, contradicting and misleading information. In this case, population genetics can be a useful tool for reconstructing and understanding the history behind the events of invasions (Ficetola et al., 2008; Bai et al., 2012; Kamath et al., 2016).

The world's most widespread invasive amphibian species is the North American bullfrog (hereafter bullfrog for short), Lithobates catesbeianus, which is native from eastern North America but currently can be found in many countries in the Americas, Europe, and Asia, where the species was introduced for frog farming and subsequently became established (Kraus, 2009). Despite recognized impacts on native populations (Both \& Grant, 2012; Schloegel et al., 2010; Li et al., 2011; Borzée et al., 2017; O'Hanlon et al., 2018), there is a small number of eradication attempts (Adams \& Pearl, 2007; Snow \& Witmer, 2010, Groffen et al., 2019), possibly as a reflection of the high cost and low rate of success of these attempts (Adams \& Pearl, 2007). The lack of information on history and paths of invasion, connectivity and dispersal among populations and their genetic structure, is one of the main reasons why management strategies tend to fail (Rollins et al., 2009).

The first country in the world to be colonized by the American bullfrog was Japan. The first importation consisted of only a few breeding pairs from New Orleans, under the initiative of the biologist Shozaburo Watase in 1918 (Maeda \& Matsui, 1999; Yanai, 2003; Hirai, 2004). New events occurred in the 1920s (Minowa et al., 2008), 1952 (Goris, 1967; Ota, 2002; Kraus, 2009), 1953, 1954 and late 1950s (Ota, 1983; Kraus, 2009) from undocumented sources.

Japan exported bullfrogs to Taiwan in 1924 and 1951 (Kraus, 2009; Santos-Barrera et al., 2009). During the same period, Japan also exported bullfrogs to Korea, first in 1959 when all individuals died, and once again in the 1970's when farming took hold, allegedly supplemented by bullfrogs originating from the USA (Groffen et al., 2019). Until recently, Taiwan province was one of the greatest bullfrog producers and exporters of the world, being the source of many introductions in Southeast Asia. Some of these introductions happened in Singapore (from the 1980s to present) (Ng \& Lim, 2010); Indonesia (1984, Indo Prima Bullfrogs' owner, personal communication); and Malaysia (Hardouin, 1997), which was one of the sources for the Cambodian population (Neang, 2010).

China reconnected with Japan in the late 1950s, after getting isolated by the split with the USSR due to political disagreements. China received bullfrogs from Japan, but these animals died without producing offspring (Li \& Xie, 2002; Bai et al., 2012; Liu \& Li, 2009; Xuan et al., 2010). Political links at that period resulted in Cuba exporting bullfrogs to China during this period (Li \& Xie, 2002; Bai et al., 2012; Liu \& Li, 2009; Xuan et al., 2010).

Cuba was one of the first countries to receive bullfrog specimens. The first known introduction happened in 1915-1916 (Kraus, 2009; Santos-barrera et al., 2009), with other two events of introduction in 1927 and 1946. All animals were exported from the USA (Borroto-Páez et al., 2015) and adapted well to the island.

In South America, bullfrogs have been introduced into 10 countries (Akmentins \& Cardozo, 2009; Kraus, 2009; Urbina-Cardona \& Nori, 2011), although no evidence of persistent populations exists in Chile and Paraguay (F. Bauer, personal communication). Brazil was the first country to be invaded, with two legal importations reported. The first happened in 1935, while Brazil was facing a turbulent political period known as the "1930s revolution". There was a pressure from some segments of society for the diversification of the 
economy (Fonseca, 2012). The government started a breeding program with 300 couples introduced by a Canadian technician named Tom Cyrril Harrison (Ferreira et al., 2002). Apart from speculation about the Canadian origin of these animals, Rueda-Almonacid (1999) reported the United States as the native source population, although he did not state the basis for that assertion. As noted by other authors ((Measey et al., 2017), the study by Rueda-Almonacid (1999) contains mistakes; thus, we prefer to disregard it

The second importation to Brazil happened in mid-1980s (Kraus, 2009) with 20 pairs from Michigan (Schloegel et al. 2010). This population is widespread in the country, especially in the state of Minas Gerais (Jorgewich-Cohen et al., in press). Later, all other South American countries received founders exclusively from Brazil (G. Laufer, ump. data; Gallardo, 2004; Kraus, 2009; Pereyra et al., 2006) during the 1980s and 1990s, as part of a general effort to improve the economy after the "lost decade" of the 1980s (Ghirardi et al., 2011; Laufer et al., 2008).

Using population genetics data from within the native range (Austin et al., 2004), some efforts were made to determine the source of alien populations and the genetic structure in Europe (Ficetola et al., 2008), western USA (Funk et al., 2011; Kamath et al., 2016), China (Bai et al., 2012), and Brazil (Prim et al., 2003; Jorgewich-Cohen et al., in press), but none of these studies aimed to reconstruct global pathways of introduction. In order to reveal the paths of invasion of the main bullfrog alien populations around the globe, combining our findings with information from previous works and historical data, we focused on the following questions: How many different lineages are there among alien clusters around the world? Through what paths did these lineages get to different countries? What is the native source of these introduced populations?

\section{Materials and Methods}

We sampled a total of 416 bullfrogs (Lithobates catesbeianus ) from 11 different countries between June 2013 and December 2017 (Supporting Information 1). Samples were obtained from feral specimens, museums and private collections; and include samples from both populations in Brazil collected by Jorgewich-Cohen et al. (in press). Tissues from liver, muscle or skin were removed and stored in $90 \%$ ethanol at $-20^{\circ} \mathrm{C}$. DNA extraction was performed with the DNeasy Blood and Tissue extraction kit (Quiagen, Valencia, CA, USA), following the manufacture's guidelines.

Seven microsatellite loci were amplified following Austin et al. (2003), with PCR conducted on a Veriti thermal cycler (Applied Biosystems) using the following thermal profile: 95degC for $7 \mathrm{~min}$ followed by 10 cycles of $95 \mathrm{deg} \mathrm{C}$ for $30 \mathrm{~s}$, touchdown from $62-57 \mathrm{degC}$ for $45 \mathrm{~s}$, and $72 \mathrm{degC}$ for $30 \mathrm{~s}$, followed by 30 cycles of $95 \mathrm{deg} \mathrm{C}$ for $30 \mathrm{~s}, 50 \mathrm{degC}$ for $30 \mathrm{~s}$, and $72 \mathrm{degC}$ for $30 \mathrm{~s}$, and final extension at $72 \mathrm{degC}$ for $7 \mathrm{~min}$. The reaction mix, with a total volume of $10 \mu \mathrm{l}$, contained $1.0 \mu \mathrm{l}$ of buffer, $0.5 \mu \mathrm{l} 2 \mathrm{mM}$ dNTPs, $0.5 \mu \mathrm{l}$ fluorescent dye (VIC for RcatJ11 and RcatJ44b; NED for RcatJ21 and RcatJ41; PET for RcatJ54 and Rcat3-2b or 6-FAM for RcatJ8; applied biosystems), $0.5 \mu \mathrm{l}$ of mixed forward and reverse primers $(5 \mu \mathrm{M}), 0.125 \mu \mathrm{l}$ Taq polymerase, $3.375 \mu \mathrm{l}$ distilled deionized water, and $3.0 \mu \mathrm{l}$ template DNA. We diluted the PCR products to a proportion of $1: 4$ and submitted them to sequencing by a third party.

We used Gene Marker ver. 2.6.3 (SoftGenetics) to score results and Microchecker (Van Oosterhout et al., 2004 ) to test for null alleles, allele dropout, and stuttering. Around $22 \%$ (91/416) of the samples were genotyped again in order to evaluate the percentage of homozygotes that were actually null alleles. Control samples were included in every procedure.

To assess current genetic structure, we performed a discriminant analysis of principal components (DAPC; Jombart et al., 2010) using the adegenet package (Jombart, 2008) on platform R (R Core Team, 2017). Samples were grouped by country of origin in cases where we could not sample in more than one site or either when we could not get enough samples to run the analysis without facing bias by using too different sample sizes between locations. Samples from Brazil were divided based on the known genetic population structure in the country (Jorgewich-Cohen et al., in press).

In order to quantify the pairwise genetic differentiation between populations observed on the DAPC, we used Jost's D index (Jost, 2008). Next, we tested the significance of the differentiation between pairs of 
populations with 10000 permutations. We subjected the results to a Benjamini and Hochberg procedure (Hochberg \& Benjamini, 1990) in order to control false discovery rates (FDR) and avoid type I error (Hauser et al., 2019). These analyzes were conducted using the DEMEtics R package (Jueterbock et al., 2010). To calculate the diversity indices: expected (He) and observed (Ho) heterozygosity, number of alleles (A) per locus, effective number of alleles (Ae) per locus, and size corrected Wright's inbreed coefficient (Fis), we used the gstudio package (Dyer, 2014), also on platform R. We checked for Hardy-Weinberg equilibrium (HWE) and linkage disequilibrium (LD) deviations through a permutation procedure with 100 batches of 1000 iterations, by performing a probability test in Genepop ver. 3.4 (Rousset, 2008). P values were corrected with the Benjamini and Hochberg procedure.

Samples that showed graphic overlap on the DAPC were considered the same genetic population for further analysis. Based on those results, we selected the most variable samples from each genetic population (Supporting Information 2) and amplified a 1047bp segment of the mitochondrial cytochrome b gene (cytb) that includes the fragment used by Austin et al. (2004). We used a combination of the primers MVZ15L (Moritz et al., 1992) and cyt-bAR-H (Goebel et al., 1999) and a thermal profile for polymerase chain reaction that consisted of $95^{\circ} \mathrm{C}$ for $10 \mathrm{~min}$, followed by 45 cycles at $95^{\circ} \mathrm{C}$ for $30 \mathrm{~s}, 50^{\circ} \mathrm{C}$ for $40 \mathrm{~s}$, and $72^{\circ} \mathrm{C}$ for $40 \mathrm{~s}$, with a final extension step at $72^{\circ} \mathrm{C}$ for $5 \mathrm{~min}$. The reaction mix, with a total volume of $25 \mu \mathrm{l}$, contained 0.15 $\mu \mathrm{l}$ Go Taq G2 Flexi DNA Polymerase (Promega corporation), $2.5 \mu \mathrm{l}$ of Go Taq flexi Buffer, $1.0 \mu \mathrm{l} 2 \mathrm{mM}$ dNTPs, $2.0 \mu \mathrm{l} 25 \mathrm{mM} \mathrm{MgCl} 2,1.0 \mu \mathrm{l}$ of each primer $(10 \mathrm{pM}), 15.35 \mu \mathrm{l}$ distilled deionized water, and $2.0 \mu \mathrm{l}$ template DNA. PCR amplification products were cleaned using Agencourt AMPure XP DNA Purification and Cleanup kit (Beckman Coulter Genomics, Brea, CA, USA), and they were sequenced by a third party using fluorescent-dye labelled terminators (ABI Prism Big Dye Terminators v. 1.1 cycle sequencing kits; Applied Biosystems, Foster City, CA, USA) with an ABI 3730XL (Applied Biosystems, Foster City, CA, USA).

We used Arlequin 3.5 (Excoffier \& Lischer, 2010) for most genetic analysis. Two diversity indices were calculated: Hd and $\pi$, described by Austin et al. (2004) respectively as "the relative frequencies of haplotypes in a population, without consideration of their relationships" and the "weighted mean of pairwise divergence among haplotypes". We also calculated the pairwise differences between the introduced populations using ७ST index and evaluated its significance by performing 10,100 permutations. P values were corrected under the Benjamini and Hochberg procedure (Hochberg \& Benjamini, 1990). Significant differentiation between populations were interpreted as cases of different native populations descendants, as it has been done before (Funk et al., 2011; Kamath et al., 2016). We used analysis of molecular variance (AMOVA) to assess the native origin of introduced populations. Information on native range is available at Austin et al. (2004), where four groups were delimited through a nested clade analysis. To perform AMOVA, we gathered populations that showed non-significant differentiation on $\vartheta \mathrm{ST}$ analysis and compared them with each of four source populations. We also performed a significance test with 10,000 permutations. The smallest value found between the four AMOVAs was considered the indication of origin for the tested population (Bai et al., 2012; Ficetola et al., 2008; Funk et al., 2011; Kamath et al., 2016).

We used Geneious ver. 10.2.3 (Kearse et al., 2012) for sequence edition and contig formation of the cytb sequences based on the chromatograms obtained from the automated sequencer. All samples were sequenced in both directions to check for potential errors. The sequences were aligned with the MAFFT (Katoh \& Standley, 2013) plugin in Geneious 10.2.3 (Biomatters) with the G-INS-I strategy. We trimmed the sequence alignment to a length of $937 \mathrm{bp}$.

For better understanding haplotype relationship, we performed a phylogenetic analysis under a maximumlikelihood (ML) based approach in RAxML ver. 8 (Stamatakis, 2014) with 100 runs, and ML branch support was evaluated by 10,000 bootstrap replicates, following the same phylogenetic method conducted by Kamath et al. (2016). We used unique haplotypes from our data and added haplotypes from Austin et al. (2003, 2004), Ficetola et al. (2008), Bai et al. (2012), and Kamath et al. (2016) to compare the relationships among haplotypes from introduced and native populations, and between those haplotypes that have not been sampled in the native range. Tree rooting was based on the outgroup method (Farris, 1982; Nixon 
\& Carpenter, 1993), and outgroup selection was based on a previous phylogenetic analysis (Pyron, 2014). We usedLithobates septentrionalis to root the tree and L. clamitans, L. okaloosae, and L. heckscheri as additional outgroup species (respective GenBank accession numbers: AY083273, AY083281, AY083286, AY083299).

\section{Results}

\section{Microsatellite analyses}

Allele dropout and stuttering measures were not significant and the presence of null alleles was indicated for all loci. Genotyping error was estimated to be $1.55 \%$. Most pairwise comparisons indicated significant deviation from Hardy-Weinberg equilibrium (Supporting Information 3) and linkage disequilibrium (Supporting Information 4) after FDR corrections.

The DAPC (Fig. 1) presented clear structure composed by four populations $(\mathrm{BRA}+\mathrm{BP} 2+\mathrm{COL}+\mathrm{ARG}+\mathrm{URU} ; \mathrm{SIN}+\mathrm{CUB} ; \mathrm{CHI}+\mathrm{KOR}+\mathrm{BEL} ; \mathrm{JAP})$. There is almost complete overlap among all South American countries, hereafter referred as Population 1 (Pop1), including the two populations described in Brazil (Jorgewich-Cohen et al., in press). Population 1 has a marginal link with Cuba, which is almost completely overlapped with samples from Singapore, together forming Population 2 (Pop2). Samples from the Republic of Korea, Belgium and China are also greatly overlapped and were considered as one unit (Pop3). Japan is completely isolated and was considered as a separated population (Pop4). Calculation of pairwise Jost's D index values (Table 1) revealed greater differentiation between Pop3 and all others. The smallest differentiation reveled is between Pop2 and Pop4, followed by the differentiation between Pop1 and Pop2. The differentiation between pairs of populations was always significant $(\mathrm{p}=0.001)$. With exception for Pop2, the observed heterozygosity (Ho) did not match expected heterozygosity (He) and both populations showed positive inbreeding values (Supporting Information 3).

\section{Cytochrome $b$ analyses}

Mitochondrial sequences provided information about the haplotypes present in each area and, together with ७ST differentiation index, we were able to indicate which areas have the same source population. We identified six haplotypes among all sampled populations (GenBank accession number: XXXXX). Three of them have been sampled on native range by Austin et al. (2004), two by Kamath et al. (2016) and one by Bai et al. (2012) on invasive areas of the USA and China. Another three haplotypes were sampled for the first time in the present work. The genetic diversity for each site is available on Table 2.

The population differentiation test was significant following the Benjamini and Hochberg procedure for all comparisons except Minas Gerais (MG)-Cuba, Brazil-Ecuador, and Singapore-Japan-China (Table 3). These results suggest that each of these groups have the same native origin and, for this reason, they were pooled together for the AMOVA. Belgium and Singapore were also nearly significant (0.05307), but were not pooled together as Belgium differentiates from the other Asian countries. AMOVA results showed similar covariance results between native range areas (Cuba + MG: 18.41 - 20.18; Asian countries: 24.05 - 31.01; Brazil + Ecuador: $17.68-26.26$; Belgium: $0.00-7.87$. (Table 4)).

Our phylogenetic analysis recovered topologies congruent with those reported by Kamath et al. (2016), with USA native west and east clades as monophyletic groups. Our haplotypes H02, H03, H04 and H06 are clustered in the western lineage; whereas haplotypes H01 and H05 are clustered in the eastern lineage.

\section{Discussion}

Several invasive species are known to have populations with low genetic diversity (Bai et al., 2012; Rollins et al., 2009; Santos et al., 2013). Besides cases where individuals from multiple native sources are put together (Kolbe et al., 2004), low genetic diversity and increased rates of inbreeding are expected due to sequential bottleneck effect (Estoup et al., 2011). Countries that have been colonized by bullfrogs not always received them directly from native sources, resulting in populations with low genetic diversity, which facilitates tracking their introduction pathway by genetic similarity. The association between genetic data and information 
from specific literature along with historical events can be helpful on understanding introduction pathways.

In our analysis, microsatellite and mitochondrial markers have shown partially consistent results. There is a consensus between markers that most areas of South America belong to the same genetic population. Two different haplotypes were found in this continent (Fig. 2). One of them (H01) is represented by $75 \%$ of the samples from Brazil and Ecuador. The other $25 \%$ is represented by H02, which is the same haplotype found among samples from Minas Gerais and Cuba on the cytb analysis. This result is consistent with the DAPC, in which Cuba has only a marginal link with the South American cluster. It also suggests that Ecuador received bullfrogs from Brazil after the secondary introduction from Michigan that might have happened before 1985 .

Although no information about the native origin of the founders of Cuban population is available [besides brief and weak conjectures based on morphotype variation by Hoffman \& Noble (1927)], it is expected that multiple events of introduction would increase genetic variation. Only one haplotype was found in Cuba, suggesting a single source of origin or a great loss of variability due to genetic drift since the last introduction event in 1946. In any case, it is reasonable to consider that samples from Cuba and Minas Gerais share their native source, as shown in the $\vartheta \mathrm{ST}$ differentiation analysis. Both regions likely received animals from Michigan, since there are no records of a secondary introduction between Cuba and Brazil.

Given the records of close ties between Cuban and Chinese bullfrog lineages in the literature, one might expect them to exhibit same haplotypes, which would differ from those in Japan, since the only documented introduction from Japan to China failed. However, two haplotypes can be found in China. One of them is the same from Cuba, while the other is found in all sampled Asian countries.

Literature indicates Japan as the source population to all countries of Asia, besides China, and genetic data partially corroborates this information. The two haplotypes found in Japan are very similar to one another, with only one polymorphic locus, being recovered as sister groups in our phylogenetic analysis. This could either mean that they came from close areas of the native range or a single haplotype suffered a mutation after introduced to Japan. One could be understandably biased in favor of the second hypothesis, due to the lack of one of these haplotypes in the rest of Asia, meaning the mutation happened after Japan exported specimens to other countries. Unfortunately this is a tricky question with many possible answers, such as: 1. Japan received this haplotype from native source after exported animals to Taiwan; 2. Japan received this haplotype before exporting animals, but it was not sampled among the exported specimens; 3 . Other countries received this haplotype from Japan, but it was lost due to genetic drift; 4 . We did not sample this haplotype in other countries by casualty. Sampling in DPR Korea Ri (2018) may be a step towards answering these questions as these specimens have been introduced from Japan possibly before 1950, and thus before a potential mutation was exported to other countries.

In any case, the haplotype H03 is widespread in Southeast Asia, including China. Several different situations are likely to have happened to cause this genetic homogeneity in Asia. The most parsimonious hypothesis is that other translocations happened from Japan to China. There are few reports that it may have happened at different periods. Although no strong evidence is available, it is likely to have happened during the Japanese invasion of China at the second Sino-Japanese war in between 1937 and 1945, and another in 1959 with three other events of exportation from Japan to China (Yang Yi, ump. data).

Another possibility is that H03 was also present in Cuba, being introduced from the same native source as the Japanese population at one of the many events of introduction. It may have colonized China, later disappearing from Cuba. This hypothesis might seem less probable, but the low number of divergent sites between these haplotypes and the shared positioning on the Western clade of the phylogenetic three supports a kinship hypothesis. The native source population of bullfrogs introduced in Asian countries is probably close to the native source of the Cuban population.

Inferring the native source of invasive populations is a hard task, especially when haplotypes found in alien populations were not sampled in the native range, as observed in the present study. AMOVA results were quite inconclusive. Finer sampling of the native area with more loci sequencing is needed to elucidate the 
native population structure (Bai et al., 2012; Kamath et al., 2016). This way, it will be possible to better understand the origin of introduced populations. However, it is worth mentioning that our results contradict prior literature. The haplotype found by Bai et al. (2012) in China is the same we found in Asia (H03) but AMOVA indicated west USA as the native source population in their analysis, while our analysis indicated the overlap zone. We found two new haplotypes in Asia that were not sample in their work. Ficetola et al. (2008) indicates the East of USA as the native source of Belgium and Greek populations, while our results indicate the West of USA as the native source of Belgium population, after adding the new discovered haplotype.

On the other hand, we concluded that USA's west zone is the native source of the population from Cuba and Minas Gerais, corroborating the results found by Kamath et al. (2016), as H02 is the same haplotype found by them in Grand Teton National Park (GenBank Accession number KX344492). This result adds questions about the origin of the haplotype H02, as literature indicates that founders of the population from Minas Gerais were imported from Michigan, located in the overlap zone.

Based on these analyzes, it is possible to conclude that Cuban and Southeast Asian haplotypes share native distribution, which is apart from South American's haplotype in Eastern lineage. However, the native origin of these haplotypes cannot be designated. Nevertheless, the information gathered from the literature (Supporting Information 5) and from genetic data in the present work helps to shed light in the history of introduction of the American bullfrog (Fig. 3), being helpful for future efforts of control that might succeed by regulating sources of introduction that keep nurturing invasive populations.

\section{Literature cited}

Adams, M.J., Pearl, C.A. (2007). Problems and opportunities managing invasive Bullfrogs : is there any hope? In F. Gherardi (Ed.),Biological invaders in inland waters - profiles, distribution and threats (pp. 679-693). Dordrecht: Springer.

Akmentins, M.S., Cardozo, D.E. (2009). American bullfrog Lithobates catesbeianus (Shaw, 1802) invasion in Argentina.Biological Invasions , 12 (4), 735-737. doi:10.1007/s10530-009-9515-3

Austin, J.D., Dávila, J.A., Lougheed, S. C., Boag, P. T. (2003). Genetic evidence for female-biased dispersal in the bullfrog, Rana catesbeiana (Ranidae). Molecular Ecology ,1-8. doi:10.1046/j.1365-294X.2003.01948.x

Austin, J. D., Lougheed, S. C., Boag, P.T. (2004). Discordant temporal and geographic patterns in maternal lineages of eastern north American frogs, Rana catesbeiana (Ranidae) and Pseudacris crucifer(Hylidae). Molecular Phylogenetics and Evolution , 32 , 799-816. doi:10.1016/j.ympev.2004.03.006

Bai, C., Ke, Z., Consuegra, S., Liu, X., Yiming, L. (2012). The role of founder effects on the genetic structure of the invasive bullfrog (Lithobates catesbeianaus) in China. Biol Invasions ,14 , 1785-1796. doi:10.1007/s10530-012-0189-x

Borroto-Páez, R., Bosch, R.A., Fabres, B.A., Osmany, A.G. (2015). Introduced amphibians and reptiles in the Cuban archipelago.Herpetological Conservation and Biology , 10 (3), 985-1012.

Borzée, A., Kosch, T.A., Kim, M., Jang, Y. (2017). Introduced bullfrogs are associated with increased Batrachochytrium dendrobatidis prevalence and reduced occurrence of Korean treefrogs. PLoS ONE , 12: e0177860. doi: 10.1371/0177860.

Both, C., Grant, T. (2012). Biological invasions and the acoustic niche: the effect of bullfrog calls on the acoustic signals of white-banded tree frogs. Biology Letters , 8 (5), 1-3. doi:10.1098/rsbl.2012.0412

Chiaverano, L.M., Wright, M.J., Holland, B.S. (2014). Movement Behavior is Habitat Dependent in Invasive Jackson's Chameleons in Hawaii. Journal of Herpetology , 48 (3), 1-10. doi:10.1670/13-150

Dyer, R. J. (2014). GSTUDIO: Analyses and functions related to the spatial analysis of genetic marker data. $\mathrm{R}$ package version, 1 . 
Estoup, A., Evans, D.M., Thomas, C.E., Lombaert, E., Facon, B., Aebi, A., Roy, H.E. (2011). Ecological genetics of invasive alien species.BioControl , 56 , 409-428. doi:10.1007/s10526-011-9386-2

Excoffier, L., Lischer, H.E.L. (2010). Arlequin suite ver 3.5: A new series of programs to perform population genetics analyses under Linux and Windows. Molecular Ecology Resources , 10 (3), 564-567. doi:10.1111/j.1755-0998.2010.02847.x

Farris, J.S. (1982). Outgroups and Parsimony. Systematic Zoology ,31 (3), 328-334.

Ferreira, C.M., Pimenta, A.G.C., Neto, J.S.P. (2002). Introdução à ranicultura. Boletim Técnico Do Instituto de Pesca, 33 , 15.

Ficetola, G.F., Bonin, A., Miaud, C. (2008). Population genetics reveals origin and number of founders in a biological invasion. Molecular Ecology , 17 , 773-782. doi: 10.1111/j.1365-294X.2007.03622.x

Ficetola, G.F., Scali, S. (2010). Invasive amphibians and reptiles in Italy. Atti. VIII Congresso Nazionale Societas Herpetologica Italica , 335-340.

Fonseca, P.C.D. (2012). A Revolução de 1930 e a Economia Brasileira.Revista EconomiA , (13), 843-866. doi: 10.1017/CBO9781107415324.004

Funk, W.C., Garcia, T.S., Cortina, G.A., Hill, R.H. (2011). Population genetics of introduced bullfrogs , Rana (Lithobates) catesbeianus, in the Willamette Valley, Oregon, USA. Biol Invasions ,13 , 651-658. doi: 10.1007/s10530-010-9855-z

Gallardo, G.G. (2004). Cría de uma rana nativa de la amazonía ecuatoriana. Abya-Yala. Quito: Centro Tecnológico de Recursos Amazónicos.

Ghirardi, R., López, J.A., Scarabotti, P.A., Steciow, M.M., Perotti, M.G. (2011). First record of the chytrid fungus in Lithobates catesbeianus from Argentina: exotic species and conservation Primer registro del hongo quitridio en Lithobates catesbeianus de Argentina : especies exoticas y conservacion. Revista Mexicana de Biodiversidad , 82 , 1337-1339.

Goebel, A.M., Donnelly, J.M., Atz, M.E. (1999). PCR Primers and Amplification Methods for 12S Ribosomal DNA, the Control Region, Cytochrome Oxidase I, and Cytochrome b in Bufonids and Other Frogs, and an Overview of PCR Primers which Have Amplified DNA in Amphibians Successfully. Molecular Phylogenetics and Evolution ,11 (1), 163-199.

Goris, R.C. (1967). The reptiles and amphibians of Hachijojima Island.Acta Herpetologica Japonica , 2 , 25-30.

Groffen, J., Kong, S., Jang, Y., Borzee, A. (2019). The invasive American bullfrog (Lithobates catesbeianus ) in the Republic of Korea: history and recommendations for population control.Management of Biological Invasions 10(3):517-535. doi:2019.10.3.08.

Hardouin, J. (1997). Elevage commercial de grenouilles en Malaisie.Tropicultura , 15 (4), 209-213.

Hauser, S., Wakeland, K., Leberg, P. (2019). Inconsistent use of multiple comparison corrections in studies of population genetic structure: Are some type I errors more tolerable than others?.Molecular ecology resources , 19(1), 144-148.

Hirai, T. (2004). Diet composition of introduced bullfrog, Rana catesbeiana, in the Mizorogaike Pond of Kyoto, Japan. Ecological Research , 19 , 375-380.

Hochberg, Y., Benjamini, Y. (1990). More powerful procedures for multiple statistical significance testing. Statistics in Medicine , 9 , 811-818.

Hoffman, W., Noble, G.K. (1927). The Bullfrog in Cuba. Copeia ,163 , 59-60. 
Hulme, P.E. (2006). Beyond control: Wider implications for the management of biological invasions. Journal of Applied Ecology ,43 (5), 835-847. doi: 10.1111/j.1365-2664.2006.01227.x

Jombart, T. (2008). adegenet: a R package for the multivariate analysis of genetic markers. Bioinformatics , 24(11), 1403-1405.

Jombart, T., Devillard, S., Balloux, F. (2010). Discriminant analysis of principal components: a new method for the analysis of genetically structured populations. BMC genetics , 11(1), 94.

Jost, L. (2008). GST and its relatives do not measure differentiation.Molecular Ecology , 17 (18), 4015-4026. doi: $10.1111 / \mathrm{j} .1365-294 \mathrm{X} .2008 .03887 . \mathrm{x}$

Jueterbock, A., Kraemer, P., Gerlach, G., Deppermann, J. (2010). DEMETICS: evaluating the genetic differentiation between populations based on Gst and $\mathrm{D}$ values. $\mathrm{R}$ package version 0.8-2.

Kamath, P.L., Sepulveda, A.J., Layhee, M. (2016). Genetic reconstruction of a bullfrog invasion to elucidate vectors of introduction and secondary spread. Ecology and Evolution , 6 (15), 5221-5233. doi: $10.1002 /$ ece3.2278

Katoh, K., Standley, D.M. (2013). MAFFT multiple sequence alignment software version 7: Improvements in performance and usability. Molecular Biology and Evolution, 30 (4), 772-780. doi: 10.1093/molbev/mst010

Kearse, M., Moir, R., Wilson, A., Stones-Havas, S., Cheung, M., Sturrock, S., Buxton, S., Cooper, A., Markowitz, S., Duran, C., Thierer, T. (2012). Geneious Basic: An integrated and extendable desktop software platform for the organization and analysis of sequence data.Bioinformatics , 28 (12), 1647-1649. doi:10.1093/bioinformatics/bts199

Kolbe, J.J., Glor, R.E., Schettino, L.R., Lara, A.C., Larson, A., Losos, J.B. (2004). Genetic variation increases during biological invasion by a Cuban lizard. Nature , 431 (1993), 177-181.

Kraus, F. (2009). Appendix A : Database of Introductions. InAlien Reptiles and Amphibians A Scientific Compendium and Analysis(pp. 133-563). Bishop Museum 1525 Bernice St. Honolulu, HI 96817 USA: Springer International Publishing.

Laufer, G., Canavero, A., Nunez, D., Maneyro, R. (2008). Bullfrog (Lithobates catesbeianus ) invasion in Uruguay. Biol Invasions , 10 (03), 1183-1189. doi:10.1007/s10530-007-9178-x

Li, Z., Xie, Y. (2002). Invasive alien species in China. Beijing: China Forestry Publishing House.

Liu, X., Li, Y. (2009). Aquaculture enclosures relate to the establishment of feral populations of introduced species. PLoS ONE , 4 (7). doi:10.1371/journal.pone.0006199

Li, Y., Ke, Z., Wang, Y., Blackburn, T.M. (2011) Frog community responses to recent American bullfrog invasions. Current Zoology57: 83-92. doi: 10.1093/57.1.83

Lowe, S., Browne, M., Boudjelas, S., De Poorter, M. (2000). 100 of the World's Worst Invasive Alien Species A selection from the Global Invasive Species Database. Published by The Invasive Species Specialist Group (ISSG) a Specialist Group of the Species Survival Commission (SSC) of the World Conservation Union (IUCN) , 12.

Maeda, N., Matsui, M. (1999). Frogs and Toads of Japan. Rev. Eds. Bun-Ichi Sogo Shuppan, Tokyo .

Measey, J., Davies, S.J., Vimercati, G., Rebelo, A., Schmidt, W., Turner, A. (2017). Invasive amphibians in southern Africa: A review of invasion pathways. Bothalia , 47 (2), 1-12.

Minowa, S., Senga, Y., Miyashita, T. (2008). Microhabitat Selection of the Introduced Bullfrogs ( Rana catesbeiana ) in Paddy Fields in Eastern Japan. Current Herpetology , 27 (2), 55-59.

Moritz, C., Schneider, C.J., Wake, D.B. (1992). Evolutionary relationships within the ensatina eschscholtzii complex confirm the ring species interpretation. Systematic Biology , 41 (3), 273-291. 
doi:10.1093/sysbio/41.3.273

Neang, T. (2010). An investigation into frog consumption and trade in Cambodia. Flora and Fauna International, Cambodia Programme, Phnom Penh, Cambodia.

Ng, T.H.U.I., Lim, K.K.P. (2010). NG TH, LIM KK. Introduced aquatic herpetofauna of Singapore's reservoirs. Cosmos , 6 (1), 117-127. doi:10.1142/S0219607710000516

Nixon, K.C., Carpenter, J.M. (1993). On outgroups. Cladistics ,9 , 413-426. doi:10.1006/clad.1993.1028

O'Hanlon, S. J., Rieux, A., Farrer, R. A., Rosa, G. M., Waldman, B., Bataille, A., Kosch, T. A., Murray, K., Brankovics, B., Fumagalli, M., Martin, M. D., Wales, N., Alvarado-Rybak, M., Bates, K. A., Berger, L., Boll, S., Brookes, L., Clare, F., Courtois, E. A., Cunningham, A. A., Doherty-Bone, T. M., Ghosh, P., Gower, D. J., Hintz, W. E., Hoglund, J., Jenkinson, T. S., Lin, C. F., Laurila, A., Loyau, A., Martel, A., Meurling, S., Miaud, C., Minting, P., Pasmans, F., Schmeller, D., Schmidt, B. R., Shelton, J. M. G., Skerratt, L. F., Smith, F., Soto-Azat, C., Spagnoletti, M., Tessa, G., Toledo, L. F., Valenzuela-Sanchez, A., Verster, R., Voros, J., Webb, R. J., Wierzbicki, C., Wombwell, E., Zamudio, K. R., Aanensen, D. M., James, T. Y., Gilbert, M. T. P., Weldon, C., Bosch, J., Balloux, F., Garner, T. W. J. \& Fisher, M. C. (2018). Recent Asian origin of chytrid fungi causing global amphibian declines. Science, 360(6389): 621-627.

Ota, H. (1983). On the herpetofauna of the Yaeyama Group, Ryukyu Archipelago. Biological Magazine Okinawa, 21, 13-19.

Ota, H. (2002). Bullfrog Rana catesbeiana. In: Handbook of Alien Species in Japan . Chijin Shoin, Tokyo: the Ecological Society of Japan.

Pereyra, M., Baldo, D., Krauczuc, E.R. (2006). La "Rana toro" em la selva atlantica interior argentina: um nuevo problema de conservacion. Cuad. Herpetol, 20 (1), 37-40.

Prim, E.C.P., Padua, J.T., Bataus, L.A.M. (2003). Variabilidade genetica da ra-touro gigante (Rana catesbeiana ) proveniente de populcoes dos estados de Goias, Para e Parana, criadas em sistema intensivo de cultivo. Ciencia Animal Brasileira , 4 (1), 1-6.

Pyron, R.A. (2014). Biogeographic analysis reveals ancient continental vicariance and recent oceanic dispersal in amphibians. Systematic Biology , 63 (5), 779-797. doi:10.1093/sysbio/syu042

R Core Team (2014). R: A language and environment for statistical computing. R Foundation for Statistical Computing, Vienna, Austria.

Ri, J. (2018). Systematics of the frogs (Anura) of our country.Biological sciences Juche 107:64-64.

Rollins, L.A., Woolnough, A.P., Wilton, A.N., Sinclair, R., Sherwin, W.B. (2009). Invasive species can’t cover their tracks: using microsatellites to assist management of starling (Sturnus vulgaris) populations in Western Australia. Molecular Ecology (2009) ,18 , 1560-1573. doi:10.1111/j.1365-294X.2009.04132.x

Rousset, F. (2008). genepop'007: a complete re-implementation of the genepop software for Windows and Linux. Molecular ecology resources , 8(1), 103-106.

Rueda-Almonacid, J.V. (1999). Situacion actual y problematica generada por la intriduccion de rana toro a Colombia. Rev. Acad. Colomb. Cienc., 23 (Suplemento especial), 367-393.

Santos-Barrera, A., Hammerson, G., Hedges, B., Joglar, R., Inchaustegui, S., Lue, K., .. Martinez-Solano, I. (2009). Lithobates catesbeianus: IUCN Red List of Threatened Species IUCN.

Santos, E.S.A., Jamieson, I.G., Santos, L.L.S., Nakagawa, S. (2013). Low genetic and morphological differentiation between an introduced population of dunnocks in New Zealand and an ancestral population in England. Biol Invasions , 15 , 185-197. doi:10.1007/s10530-012-0278-x 
Schloegel, L.M., Ferreira, C.M., James, T.Y., Hipolito, M., Longcore, J.E., Hyatt, A.D. (2010). The North American bullfrog as a reservoir for the spread of Batrachochytrium dendrobatidis in Brazil. Animal conservation 1, 53-61. doi:10.1111/j.1469-1795.2009.00307.x

Snow, N.P., Witmer, G. (2010). American Bullfrogs as Invasive Species : A Review of the Introduction, Subsequent Problems, Management Options, and Future Directions. Proceedings of the Vertebrate Pest Conference 24(24).

Stamatakis, A. (2014). RAxML version 8: a tool for phylogenetic analysis and post-analysis of large phylogenies. Bioinformatics , 30(9), 1312-1313.

Urbina-Cardona, J.N., Nori, J. (2011). Areas vulnerables a la invasion actual y futura de la rana toro ( Lithobates catesbeianus : Ranidae ) en Colombia : estrategias propuestas para su manejo y control.Biota Colombiana , 12 (2), 23-34.

Van Oosterhout, C., Hutchinson, W.F., Wills, D.P.M., Shipley, P. (2004). MICRO-CHECKER: Software for identifying and correcting genotyping errors in microsatellite data. Molecular Ecology Notes , 4 (3), 535-538. doi:10.1111/j.1471-8286.2004.00684.x

Xuan, L., Yiming, L., Mcgarrity, M. (2010). Geographical variation in body size and sexual size dimorphism of introduced American bullfrogs in southwestern China. Biol Invasions , 12 , 2037-2047. doi:10.1007/s10530-009-9606-1.

\section{Tables}

Tables are in a separated file.

\section{Figure legends}

Figure 1. Discriminant analysis of principal components of genetic variation among microsatellite samples of Lithobates catesbeianus invasive populations.

Figure 2. Parsimony consensus tree with haplotypes from native range (Austin et al., 2004), Europe (Ficetola et al., 2008), China (Bai et al., 2012), non-native areas of USA (Kamath et al., 2016), and samples from the present work. Clades East and West refer to distribution in the native range (Austin et al., 2004). Map contains the haplotypes' distribution around the world. Color legend follows both map and phylogeny. Terminal labels with GenBank accession number starting with AY correspond to haplotypes found in the native distribution (Austin et al., 2004) and labels starting with KX correspond to haplotypes found in the invasive distribution in the USA (Kamath et al., 2016).

Figure 3. Bullfrog invasion pathways diagram based on literature information. Arrows and dates indicate the direction and date of each event of invasion, question marks indicate unknown source of introduction, and crosses indicates supposedly non-successful establishment of the introduced animals. The green arrow indicates possible successful genetic flow in disagreement with previous literature.

\section{Data Accessibility Statement}

DNA sequences: Genbank accessions XXXXXX-XXXXXX; XXXX XXX: XXXXXXXXXX

\section{Competing Interests Statement}

\section{Author Contribution}

Gabriel Jorgewich-Cohen: Conceptualization (equal); data curation (lead); formal Analysis (equal); investigation (equal); methodology (equal); project administration (equal); writing - original draft (lead); validation (lead); visualization (equal). Rachel Montesinos: Formal Analysis (equal); investigation (equal); methodology (supporting). Rafael dos Santos Henrique: Visualization (equal); writing - review \& editing (lead). Luis Felipe Toledo: Data curation (supporting); resources (supporting). Amael Borzee: Data curation (supporting); resources (supporting). Yang Yi: Data curation (supporting); resources (supporting). Wang Fei: Data 
curation (supporting); investigation (supporting). Takeshi Igawa: Data curation (supporting); resources (supporting). Juan Manuel Guayasamin: Data curation (supporting); resources (supporting). Gabriel Laufer: Data curation (supporting); resources (supporting). Wilmar Bolivar: Data curation (supporting); resources (supporting). Ariel Rodriguez: Data curation (supporting); resources (supporting). Taran Grant: Conceptualization (equal); funding acquisition (lead); methodology (equal); project administration (equal); resources (lead); supervision (lead); writing - review \& editing (equal).

\section{Acknowledgements}

We thank C. A. Agostinho, C. F. B. Haddad, M. T. Rodrigues, R. Lingnau, R. B. Paradero, E. Grou, V. Silva, R. Maneyro, J. Faivovich, G. Louette, S. Devisscher, A. Martel and K. P. Lim for sample donations; and M. Targino and C. Rossi for laboratory and analysis assistance. This research was supported by the Sao Paulo Research Foundation (FAPESP \#2012/10000-5, \#2016/25358-3, \#2018/15425-0, \#2019/18335-5) and Conselho Nacional de Desenvolvimento Científico e Tecnológico (CNPq \#134290/2015-1, \#300896/2016-6, \#306823/2017-9).

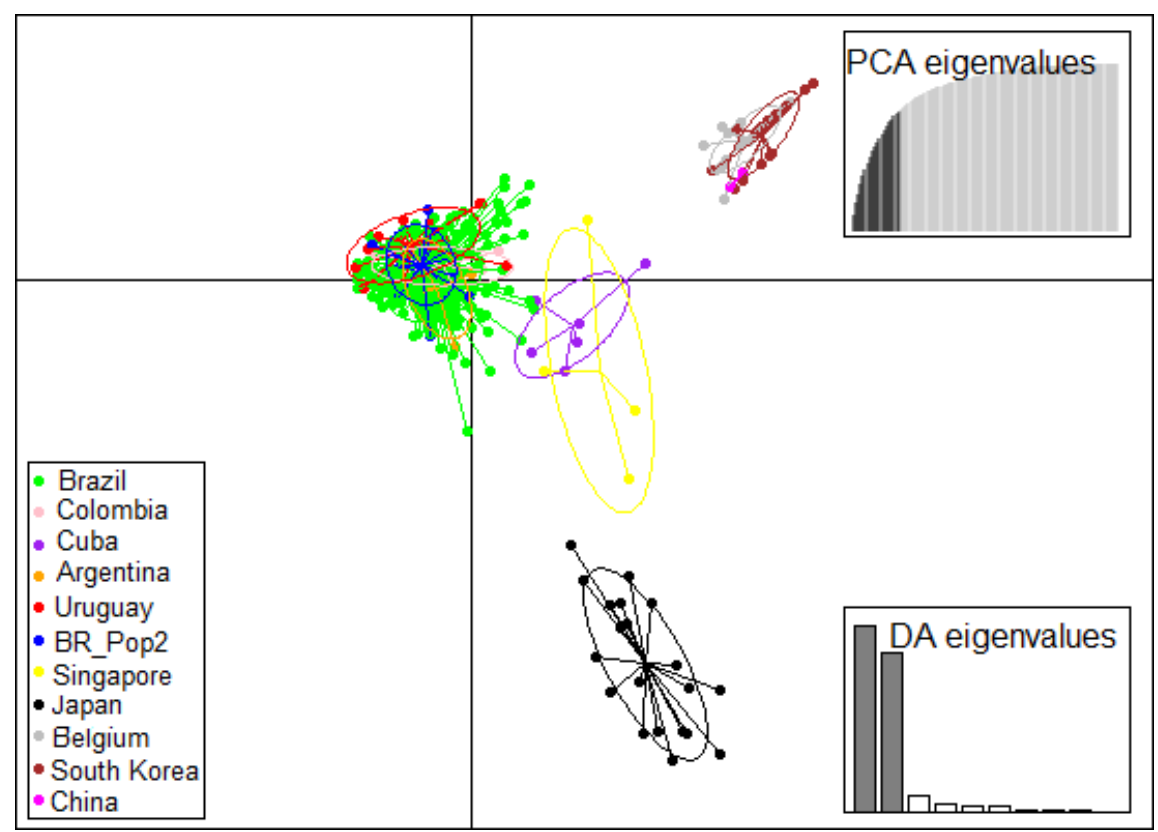



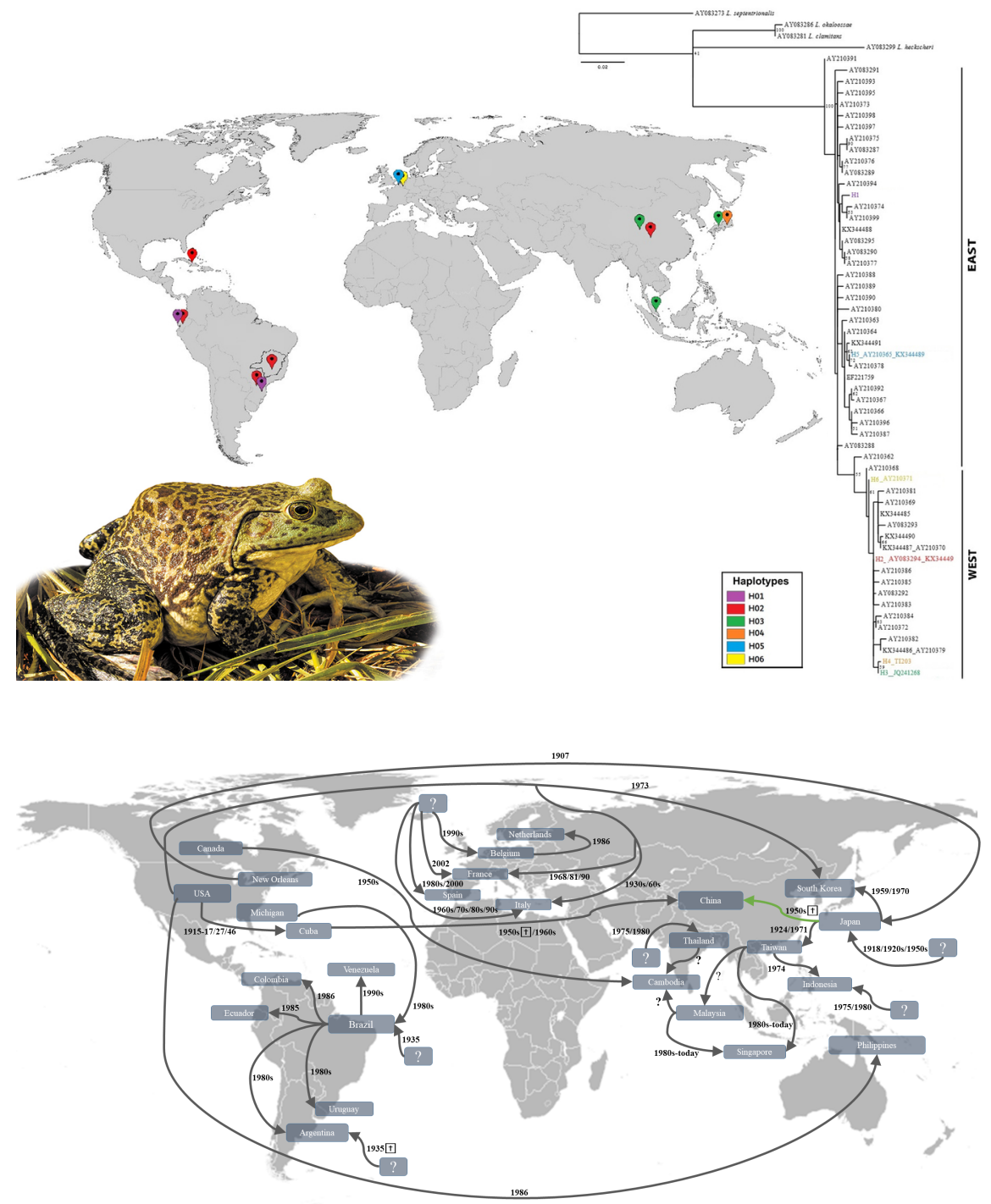